Although the motion is mainly horizontal, the large amplitudes of the oscillation at high altitudes are accompanied by considerable vertical displacements of the atmospheric layers. These are of the order of a $\mathrm{km}$. at the $100 \mathrm{~km}$. level, but increase exponentially with height until they begin eventually to be damped by the increasing kinematic viscosity and thermal conduction. It is thus possible that the anomalous variation of height and ionization of the $F_{2}$ layer, as reported by Appleton and Naismith ${ }^{5}$ and Martin and Pulley ${ }^{6}$, might be associated with the semidiurnal oscillation of the atmosphere. Were it not for the retardation by viscosity and conduction, the upper layers would be expected to reach their maximum height at about 9.30 a.m. and 9.30 p.m.

A detailed report of this investigation will appear elsewhere.

40 Grantchester Road, Cambridge.

August 22 .

${ }^{1} \mathrm{~S}$. Chapman, S. K. Pramanik and J. Topping, Beiträge zur Geophysik, 33, 246 (1931).

${ }_{2}^{2}$ Proc. Roy. Soc., A, 126, 169, 728 (1929); Mem. Roy. Met. Soc., 4, No. 35 (1932); Proc. Roy. Soc., A, 156, 378 (1936).

${ }^{3}$ S. Chapman, Phil. Trans., A, 218, 1 (1919).

'Quart. J. Roy. Met. Soc., 61, 285 (1935).

Proc. Roy. Soc., A, 150, 697 (1935).

Proc. Roy. Soc., A, 154, 455 (1936).

\section{Fossil Human Remains from Kanam and Kanjera, Kenya Colony}

Is NATURE of March 9, 1935 a letter appeared from Prof. P. G. H. Boswell upon this subject, and I should like to comment upon certain issues raised. Prof. Boswell wrote: "Unfortunately, it has not proved possible to find the exact site of either discovery, since the earlier expedition (of 1931-32) neither marked the localities on the ground nor recorded the sites on a map". This sentence gives the impression that no adequate measures were taken to record the position of the discoveries. Actually, steps were taken which would have proved adequate had not all the photographs, taken especially for the purpose, failed owing to an unsuspected hole in the bellows of the camera. I did not record the sites on a map because there was no map of sufficient accuracy available, and I had not the means of making one at that time. I might have tried to obtain the services of a surveyor, but that would have been costly and I was saving all the money I could for a second visit to Oldoway, which I, at the time, believed was more important.

When we went to Kanam and Kanjera, we had only recently returned from Oldoway, where the geologists had decided that the evidence for the great age of the Oldoway skull was geologically sound. I had accepted their verdict ${ }^{1}$ (which was proved to be wrong after my return to England ${ }^{2}$ ) and I had consequently withdrawn my earlier attack ${ }^{3}$. When I was at Kanam the evidence of Oldoway was once more being questioned ${ }^{4}$, and so $I$ was arranging to revisit Oldoway with $\mathrm{Mr}$. Wayland, the director of the Geological Survey of Uganda, in order to reexamine the evidence.

Later events have proved that this was an error of judgment, and that it would have been better to get a surveyor for Kanam and abandon the idea of revisiting Oldoway, but it is easy to be wise after the event. I believed at the time that the sites were adequately marked.
In spite of everything, I maintain that I showed Prof. Boswell the actual stratum from which the Kanam mandible was obtained, as well as the position within circumscribed limits. At Kanjera I showed him the exact spot where the residual mound of deposits had stood which yielded the Kanjera No. 3 skull in situ. We ourselves dug away most of the mound in 1932, and the small remaining portion had been eroded away. But the fact that I did show Prof. Boswell the site is proved by a small fragment of bone picked up there in 1935 which fits one of the 1932 pieces.

Another issue raised by Prof. Boswell is connected with the accidental use of a wrong photograph. $\mathrm{He}$ wrote : "Moreover, the photograph of the site where the mandible was found, exhibited with the jaw fragment at the Royal College of Surgeons, was, through some error, that of a different locality; and the deposits (said to be clays) are in fact of entirely different rock (volcanic agglomerate)." This sentence is even more misleading than the previous one, and there are two points which I must discuss.

First of all, the accidental use of a wrong photograph. As already mentioned, my own photographs of the site all failed, and I consequently had to make use of photographs taken by other members of the expedition. In view of this, I carefully refrained from using any photographs as evidence in connexion with my claim for the antiquity of the Kanam mandible, and only used them to show the general nature of the sites. I had among others a photograph taken by Miss Kendrick and marked on the back "Kanam West, site of Deinotherium tooth". Owing to a mistake on my part, which I freely admit and deeply regret, this was taken to be a picture of the site where the deinotherium tooth was found which led to the discovery of the human mandible fragment. I therefore used it in good faith to give a general view of the site. In 1935, we found that this picture was of a different part of the Kanam West exposures (about 400 yards away) where the first deinotherium tooth found in the area came from.

The sentence quoted above ends "and the deposits (said to be clays) are in fact of entirely different rock (volcanic agglomerate)". From articles in the Press (see Discovery, April 1935, etc.) and from conversations I have had, it is clear that this sentence has been very widely interpreted both in England, on the Continent and in the United States, as meaning in effect "Boswell says Leakey does not know the difference between a clay and a volcanic agglomerate!" I understand from Prof. Boswell that he did not mean this at all, and that the words were only meant to mean that the deposits visible in the wrong picture are agglomerates whereas the deposits at the site itself are (as I said) clays.

There are several other issues that $I$ would like to discuss, including the meaning of the word 'horizon' in connexion with the Kanjera finds. I used the word in the sense defined by several geological text-books, but it seems to have a different meaning for Prof. Boswell. I will not, however, trespass further on space of NATURE, as I hope to have an opportunity before long to discuss the matter further.

Great Munden,

L. S. B. Leakey.

Ware,

Herts.

1 NATURE, 128, 724 (1931).

NATURE, 131, 397 (1933).

stone Age Cultures of Kenya Colony", p. 14 et seq. 